\title{
A Nationwide Enumeration of the Surgical Workforce, its Production and Disparities in Operative Productivity in Liberia
}

\author{
H. A. Adde ${ }^{1}$ (1) A. J. van Duinen ${ }^{1,2}$ - L. M. Sherman ${ }^{3}$ B. C. Andrews ${ }^{4}$ Ø Ø. Salvesen ${ }^{5}$ N. K. Dunbar ${ }^{6}$. \\ A. J. Bleah ${ }^{7}$ T. G. Weiser ${ }^{8,9,10}$ - H. A. Bolkan ${ }^{1,2}$
}

Accepted: 29 October 2021/Published online: 27 November 2021

(C) The Author(s) 2021

\begin{abstract}
Background Any health care system that strives to deliver good health and well-being to its population relies on a trained workforce. The aim of this study was to enumerate surgical provider density, describe operative productivity and assess the association between key surgical system characteristics and surgical provider productivity in Liberia. Methods A nationwide survey of operation theatre logbooks, available human resources and facility infrastructure was conducted in 2018. Surgical providers were counted, and their productivity was calculated based on operative numbers and full-time equivalent positions.

Results A total of 286 surgical providers were counted, of whom 67 were accredited specialists. This translated into a national density of 1.6 specialist providers per 100,000 population. Non-specialist physicians performed 58.3 percent (3607 of 6188) of all operations. Overall, surgical providers performed a median of 1.0 (IQR 0.5-2.7) operation per week, and there were large disparities in operative productivity within the workforce. Most operations (5483 of 6188) were categorized as essential, and each surgical provider performed a median of 2.0 (IQR 1.0-5.0) different types of essential procedures. Surgical providers who performed 7-14 different types of essential procedures were more than eight times as productive as providers who performed $0-1$ essential procedure (operative productivity ratio $=8.66$, 95\% CI 6.27-11.97, $P<0.001$ ).

Conclusion The Liberian health care system struggles with an alarming combination of few surgical providers and low provider productivity. Disaggregated data can provide a high-resolution picture of local challenges that can lead to local solutions.
\end{abstract}

H. A. Adde

haavarad@stud.ntnu.no

1 Department of Clinical and Molecular Medicine, Faculty of Medicine and Health Sciences, NTNU-Norwegian

University of Science and Technology, Post Box 8905, 7491 Trondheim, Norway

2 Department of Surgery, St Olav's Hospital, Trondheim University Hospital, Trondheim, Norway

3 A. M. Dogliotti College of Medicine, University of Liberia, Monrovia, Liberia

4 Liberia College of Physicians and Surgeons, Monrovia, Liberia
Department of Public Health and Nursing, Faculty of Medicine and Health Sciences, NTNU-Norwegian University of Science and Technology, Trondheim, Norway

6 Research Unit, Ministry of Health, Monrovia, Liberia

7 Esther and Jereline Medical Center, Ganta, Liberia

8 Department of Surgery, Stanford University, Stanford, USA

9 Stanford-Surgery Policy Improvement Research and Education Center, Department of Surgery, Stanford University, Palo Alto, USA

10 Department of Clinical Surgery, University of Edinburgh, Edinburgh, UK 


\section{Introduction}

The global burden of disease is shifting towards noncommunicable diseases and injuries [1, 2]. All-cause mortality will not decrease at the same pace as in previous decades unless major efforts are implemented to reorient health systems [2]. Affordable surgical services should be an essential part of any health care system [3, 4]. A trained surgical workforce is key to deliver safe surgical services $[3,4]$, but the global workforce of specialist surgical providers is maldistributed and to a large extent inadequate to cover population needs, especially in low-income countries $[3,5]$.

The density of specialist surgical providers has been described as a key metric to benchmark and monitor development worldwide [3]. To complement global metrics, subnational analysis has been highlighted as an important tool to reveal in-country challenges $[6,7]$. Operative productivity is a measure that has been used to describe surgical systems both at the provider level [8] and at the facility level [9]. Although surgical facilities are often highlighted as the nucleus of surgical systems [6], granular data on surgical provider specialization, geographic distribution and productivity can add valuable information [10]. However, there is no consensus on how to report on these detailed variables and limited knowledge about the relationship between them in settings where resources are sparse.

Liberia is located on the shoreline of West-Africa and is ranked 175 out of 189 nations on the United Nations Human Development Index [11]. More than a decade of civil war and the more recent Ebola virus outbreak has weakened the health system [12], and surgical volumes are critically low [13, 14]. The country has one medical school that is located in the capital Monrovia [15], and the annual output of medical graduates averages 25 doctors per year [16]. To strengthen surgical services, the Liberia College of Physicians and Surgeons was established in 2013, but the postgraduate program is struggling with deficits in human resources to teach and supervise trainees as well as infrastructural shortages [16].

There is a need to strengthen the surgical sector if universal health coverage is to be achieved in Liberia. A baseline assessment of the surgical system, including its workforce, is a necessary first step before launching strengthening initiatives $[6,17]$. Consequently, this study aimed to enumerate surgical provider density, describe operative productivity and assess the association between key surgical system characteristics and surgical provider productivity.
Material and methods

\section{Data collection}

A nationwide survey of surgical activity, human resources and infrastructure in Liberia was conducted between 20 September and 8 November 2018. All healthcare facilities that performed surgical procedures requiring general, regional or local anaesthesia within an operating theatre the year prior to the data collection were eligible for inclusion. In each facility, structured interviews were conducted to collect information on surgical providers. The Lancet Commission on Global Surgery hospital assessment tool was used to quantify facility infrastructure and equipment. Operation theatre logbooks were reviewed, and a sample of four preselected months from the logbooks (October, January, April and July) was transcribed into a Microsoft Excel dataset (Microsoft, Redmond, Washington, USA). The data collection has been described in detail elsewhere [14].

\section{Definitions}

A surgical provider was defined as any provider listed as the main operator in the 4-month sample from the operation theatre logbooks. All surgical providers were categorized according to specialization level: accredited specialist, specialist program resident, non-specialist physician or non-physician (physician assistant, midwife or nurse). The provision of safe surgery was defined in-line with previous studies $[18,19]$ and included the availability of eight infrastructural items at the facility: pulse oximeter, adult bag mask, oxygen, suction, intravenous fluids, sterile gloves, skin preparation solution and a functioning sterilizer.

All operations requiring general, regional or local anaesthesia within an operating theatre were defined as a surgical procedure [20]. A surgical procedure listed as especially cost-effective by the third edition of the World Bank Disease Control Priorities was defined as essential [4]. Geographic areas were categorized according to population poverty levels (proportion of population living in absolute poverty), as defined by the Liberian Household Income and Expenditure Survey [21].

\section{Analysis}

Surgical provider density was calculated per 100,000 population [3]. Population numbers were extracted from the Liberian Household Income and Expenditure Survey [21] and scaled up using the population growth rate from 
the latest population census [22]. Calculating essential surgical procedures as a proportion of total surgical numbers has previously been proposed as a method to describe the impact level of surgical volumes [23], and this method was applied. Also, the number of different essential procedures performed was counted for each surgical provider, giving a range of essential surgical procedures performed [14]. A score that combines the presence of multiple infrastructure and equipment items [14] was used to describe the level of infrastructure available to each surgical provider in the facility they worked. Surgical providers that practiced in several facilities were allocated to the facility where they spent most time.

The basic unit for calculating operative productivity was the surgical provider, and all types of operations performed were included. Surgical provider productivity was defined as the total number of operations performed as first operator per full-time equivalent position per week, as described by a previous study [8]. The length and the size (full time or part time) of a surgical provider working position over the study period were combined into one full-time equivalent position measure. Consequently, provider productivity was adjusted for working position length and size, leaving a measure of weekly performed operations per surgical provider. The operations and working position for a provider working in multiple facilities were combined into one productivity measure for that provider.

A mixed Poisson regression model was built in RStudio version 1.3.1093 [24] with lme4 [25] to perform linear mixed analysis of the association between surgical system characteristics and surgical provider productivity. The basic unit included in the regression model was the surgical providers, and these were described by individual and facility characteristics. The facility characteristics were shared for providers working in the same surgical facility. One regression model was used to assess the association between variables at the individual level and at the facility level and surgical provider productivity. Surgical system variables were included as fixed effects and surgical provider identification as a random effect. The effect measure is an operative productivity ratio (OPR). An OPR of two implies a twofold increase in productivity compared with the reference. A multivariable model was run adjusting for surgical provider full-time equivalent position, number of facility beds and number of facility operation theatres. The full-time equivalent position was included as an offset variable.

\section{Ethical considerations}

The Institution Review Board, University of Liberia granted ethical clearance (number FWA00004982) and the Regional Committee for Medical and Health Research
Ethics in central Norway exempted this study from review (number 2018/1008).

\section{Results}

\section{The surgical workforce}

A total of 286 surgical providers were registered in the operation theatre logbook of 4-month sample, and 67 of these were accredited specialists (Table 1). Of the specialists, 48 worked in the capital area. Nineteen surgical providers were practicing in more than one facility. A major part of the surgical workforce were non-specialist physicians (152 of 286), and these performed 58.3 percent of all operations (3607 of 6188). The national density of all surgical providers was 6.7 per 100,000 population, and the density of specialists, including anaesthesiologists, was 1.6 per 100,000 population. There were three specialist anaesthesiologists working in three different facilities at the time of the data collection. Areas with higher poverty had lower specialist density ( 0.7 per 100,000 population) compared with areas with lower poverty (3.6 per 100,000 population). Between all 15 counties (administrative areas), the specialist density ranged from 0 to 3.6 per 100,000 population. Montserrado County, where the capital Monrovia is located, had the highest density of surgical providers (Fig. 1). Counties with high population poverty had the lowest density of surgical providers (Fig. 2).

\section{Operative productivity}

The median provider productivity was 1.0 (IQR 0.5-2.7) operation per week (Table 1), and there were large differences in operative productivity (Fig. 3). The most productive 10 percent (28 of 286) of the surgical workforce performed 36 percent (2237 of 6188) of the total surgical volume. Eighteen of the 28 highest performing providers were non-specialist physicians. The 28 most productive providers were spread across 19 different surgical facilities.

\section{Essential and other surgical procedures}

Of all surgical procedures performed, 88.6 percent (5483 of 6188) were categorized as essential (Table 1). Specialists performed 77.8 percent (1269 of 1631) essential procedures compared with 92.3 percent (3329 of 3607) essential procedures performed by non-specialist physicians. Surgical providers performed a median of 2.0 (IQR 1.0-5.0) different types of essential procedures. Specialists working in areas with high population poverty performed a median of 5.0 (IQR 1.5-6.5) different types of essential procedures. Other surgical procedures constituted 11.4 percent of the 
Table 1 Density and characteristics of surgical providers by specialization level

\begin{tabular}{|c|c|c|c|c|c|}
\hline & $\begin{array}{l}\text { Specialists } \\
n=67\end{array}$ & $\begin{array}{l}\text { Residents } \\
n=48\end{array}$ & $\begin{array}{l}\text { Non-specialist physicians } \\
n=152\end{array}$ & $\begin{array}{l}\text { Non-physicians } \\
n=19\end{array}$ & $\begin{array}{l}\text { Total } \\
n=286\end{array}$ \\
\hline \multicolumn{6}{|l|}{ Provider characteristics $^{\mathrm{a}}$} \\
\hline \multicolumn{6}{|l|}{ Working position } \\
\hline Full time & $43(64.2)$ & 19 (39.6) & $72(47.4)$ & $7(36.8)$ & $141(49.3)$ \\
\hline Part time & $23(34.3)$ & $29(60.4)$ & $80(52.6)$ & $10(52.6)$ & $142(49.7)$ \\
\hline Missing & $1(1.5)$ & $0(0)$ & $0(0)$ & $2(10.5)$ & $3(1.1)$ \\
\hline \multicolumn{6}{|l|}{ Nationality } \\
\hline Liberian & $32(47.8)$ & $46(95.8)$ & $123(80.9)$ & $18(94.7)$ & 219 (76.6) \\
\hline Foreign & $35(52.2)$ & $2(4.2)$ & $29(19.1)$ & $0(0)$ & $66(23.1)$ \\
\hline Missing & $0(0)$ & $0(0)$ & $0(0)$ & $1(5.3)$ & $1(0.4)$ \\
\hline \multicolumn{6}{|l|}{ Operations per week ${ }^{b}$} \\
\hline All providers & $1.0(0.5-2.8)$ & $0.7(0.3-2.4)$ & $1.3(0.5-2.8)$ & $0.7(0.3-1.4)$ & $1.0(0.5-2.7)$ \\
\hline Area with lower poverty ${ }^{\mathrm{c}}$ & $0.8(0.5-3.1)$ & $0.7(0.3-1.3)$ & $1.4(0.5-3.0)$ & $0.9(0.6-1.9)$ & $0.9(0.5-2.5)$ \\
\hline Area with intermediate poverty ${ }^{\mathrm{d}}$ & $1.5(0.8-3.1)$ & $0.5(0.3-1.0)$ & $1.3(0.5-3.1)$ & $0.5(0.2-1.2)$ & $1.1(0.4-3.0)$ \\
\hline Area with higher poverty ${ }^{\mathrm{e}}$ & $0.9(0.5-1.7)$ & $3.7(0.7-5.6)$ & $1.1(0.2-2.2)$ & $1.0(0.3-2.3)$ & $1.1(0.3-2.4)$ \\
\hline \multicolumn{6}{|l|}{ Surgical provider density ${ }^{\mathrm{f}}$} \\
\hline All providers & 1.6 & 1.1 & 3.5 & 0.4 & 6.7 \\
\hline Area with lower poverty ${ }^{c}$ & 3.6 & 2.7 & 2.8 & 0.3 & 9.3 \\
\hline Area with intermediate poverty ${ }^{\mathrm{d}}$ & 0.7 & 0.1 & 4.0 & 0.5 & 5.2 \\
\hline Area with higher poverty & 0.7 & 1.1 & 3.5 & 0.7 & 5.9 \\
\hline \multicolumn{6}{|l|}{ Surgical procedures } \\
\hline \multicolumn{6}{|l|}{ Four-month surgical volume $e^{g}$} \\
\hline All procedures & 1631 & 807 & 3607 & 143 & 6188 \\
\hline Essential procedures & $1269(77.8)$ & $748(92.7)$ & $3329(92.3)$ & $137(95.8)$ & $5483(88.6)$ \\
\hline Other procedures & $362(22.2)$ & $59(7.3)$ & $278(7.7)$ & $6(4.2)$ & $705(11.4)$ \\
\hline \multicolumn{6}{|l|}{ Range of essential procedures ${ }^{b}$} \\
\hline All procedures & $3.0(2.0-7.0)$ & $2.0(1.0-5.0)$ & $2.0(1.0-5.0)$ & $1.0(1.0-2.0)$ & $2.0(1.0-5.0)$ \\
\hline Obstetrics/gynaecology & $1.0(0-2.0)$ & $1.0(0-2.0)$ & $1.0(1.0-2.0)$ & $1.0(1.0-1.0)$ & $1.0(1.0-2.0)$ \\
\hline General surgery & $2.0(0-3.0)$ & $0.5(0-2.0)$ & $1.0(0-2.0)$ & $0(0-0)$ & $1.0(0-2.0)$ \\
\hline Injury/orthopaedics & $1.0(0-2.0)$ & $0(0-1.0)$ & $0(0-1.0)$ & $0(0-0)$ & $0(0-1.0)$ \\
\hline Area with lower poverty ${ }^{c}$ & $3.0(2.0-7.0)$ & $2.0(1.0-5.0)$ & $2.0(1.0-4.0)$ & $1.5(0.3-2.0)$ & $2.0(1.0-5.0)$ \\
\hline Area with intermediate poverty ${ }^{\mathrm{d}}$ & $3.5(1.0-6.3)$ & $1.0(1.0-2.0)$ & $3.0(1.0-6.0)$ & $1.0(1.0-2.0)$ & $2.0(1.0-5.3)$ \\
\hline Area with higher poverty ${ }^{\mathrm{e}}$ & $5.0(1.5-6.5)$ & $3.0(1.0-5.0)$ & $2.5(1.0-6.3)$ & $1.0(0.5-2.0)$ & $2.0(1.0-5.0)$ \\
\hline
\end{tabular}

${ }^{\mathrm{a}}$ Number $(\%) ;{ }^{\mathrm{b}}$ Median (IQR); ${ }^{\mathrm{c}}$ Area where $<30 \%$ of people live in absolute poverty; ${ }^{\mathrm{d}}$ Area where $30-70 \%$ of people live in absolute poverty; ${ }^{\mathrm{e}}$ Area where $>70 \%$ of people live in absolute poverty; ${ }^{\mathrm{f}}$ Density per 100,000 population; ${ }^{\mathrm{g}} 240$ operations excluded due to unknown procedure name and/or surgical provider

total surgical volume (Table 1), and specialists performed a median of 2.0 (IQR 1.0-3.0) other procedures, while residents, non-specialist physicians, and non-physicians performed 1.0 (IQR 0-1.0), 0 (IQR 0-2.0) and 0 (IQR 0-0) other surgical procedures, respectively.

\section{Surgical system variables and their association with provider productivity}

Surgical providers who performed 7-14 different essential procedures had an operative productivity ratio (OPR) 8.66 (95\% CI 6.27-11.97, $P<0.001$ ) times higher than providers who performed $0-1$ essential procedures (Table 2). Surgical providers working in private non-profit facilities were almost three times as productive $(\mathrm{OPR}=$ $2.82,95 \%$ CI $1.71-4.65, P<0.001)$ as providers working in governmental facilities (Table 3). However, providers working in facilities with a better infrastructure score (165) did not have a significantly higher productivity $(\mathrm{OPR}=$ $1.17,95 \%$ CI $0.73-1.88, P=0.512)$. Shortages of certain safe surgery items like oxygen $(\mathrm{OPR}=0.62,95 \% \mathrm{CI}$ $0.42-0.90, P=0.012$ ) and blood supply (OPR $=0.60,95 \%$ CI $0.39-0.93, P=0.020)$ seemed to be associated with provider productivity (Table 4 ). 


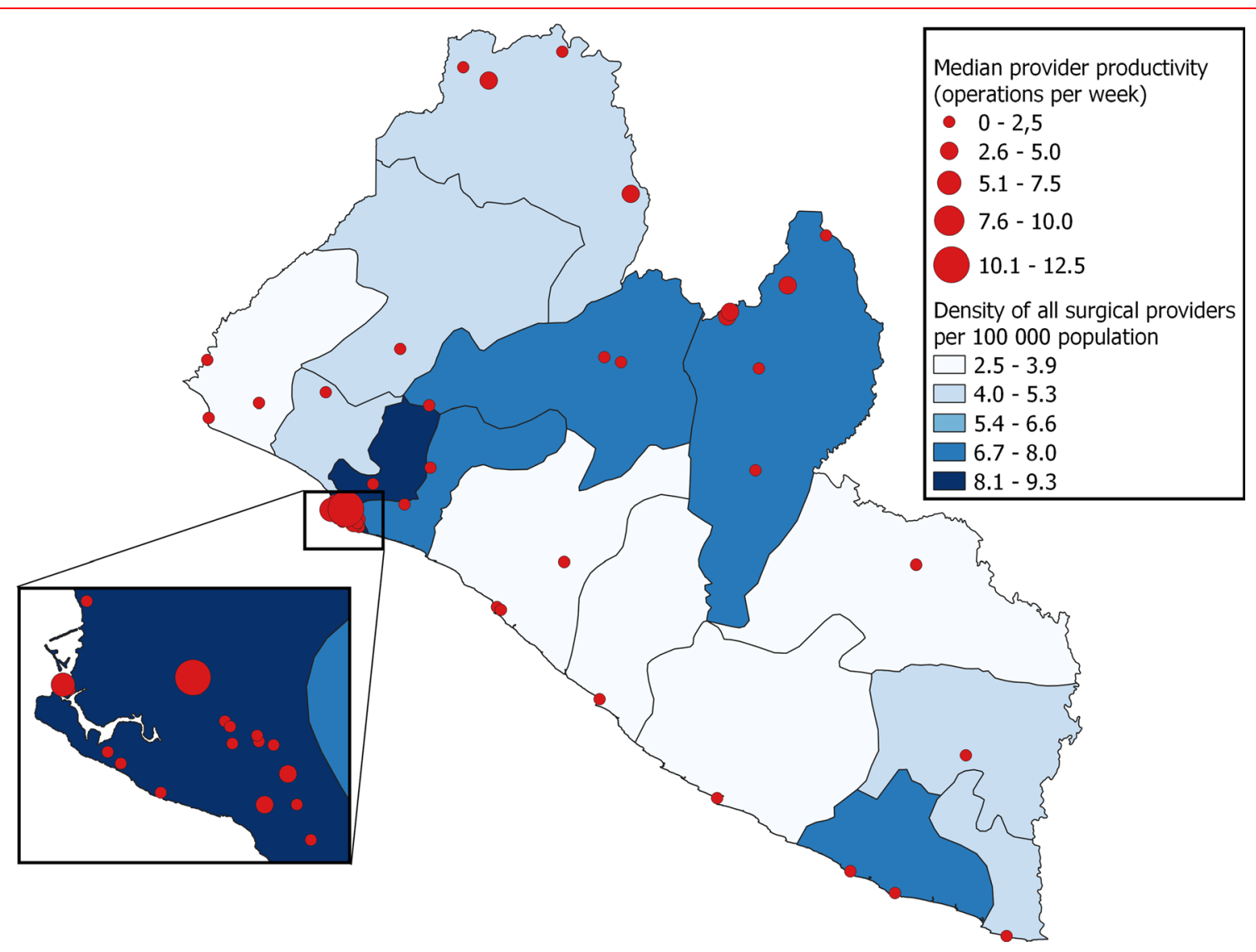

Fig. 1 Geographic distribution of the surgical workforce and surgical provider productivity

Fig. 2 Density of surgical providers and proportion of people living in absolute poverty. Each data point represents one of the fifteen counties (administrative areas) in Liberia

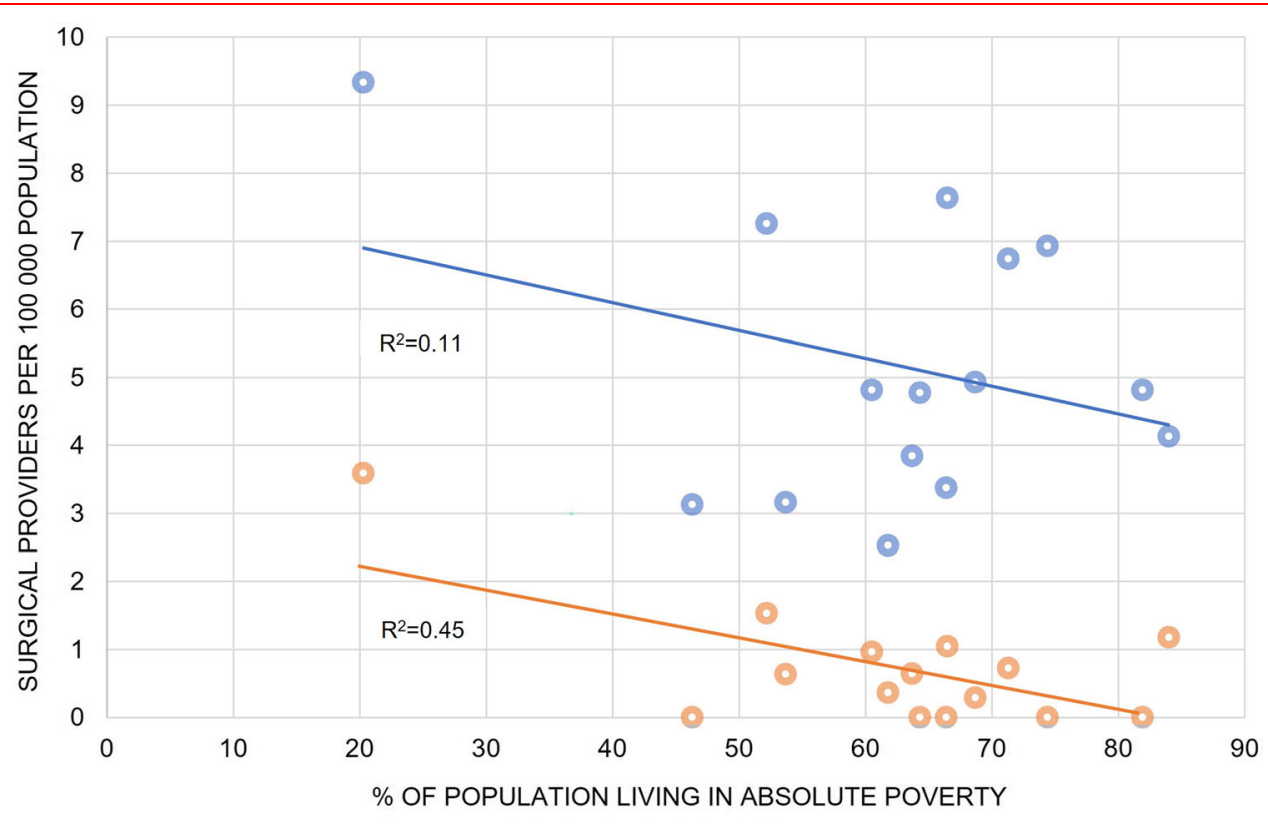

All providers 
Fig. 3 Cumulative percentage of surgical providers by cadre and their operative productivity

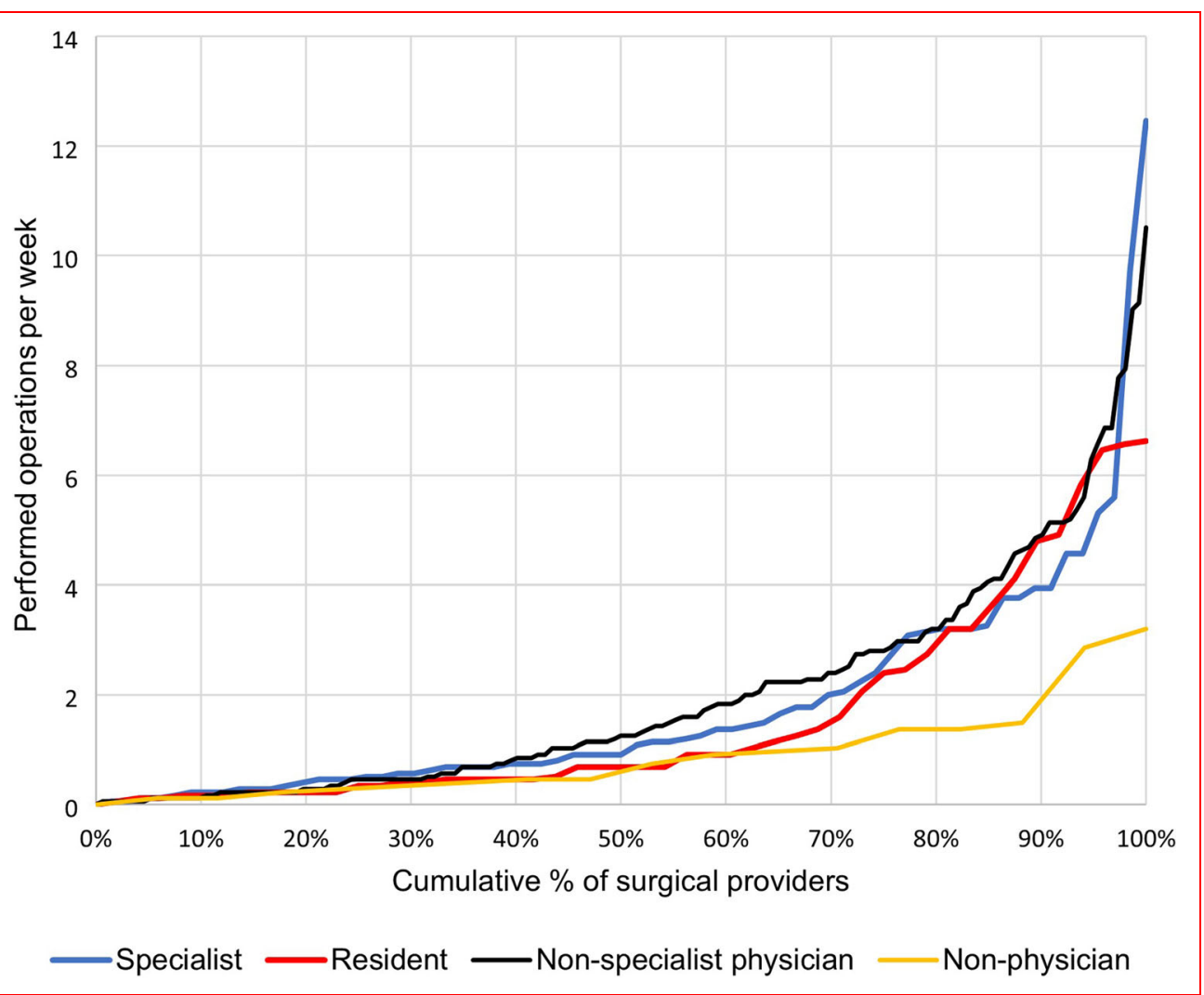

\section{Discussion}

This study aimed to describe the surgical workforce, its production and variables associated with surgical provider productivity in Liberia. The density of specialist providers was 1.6 per 100,000 population, and 58 percent of all operations were performed by non-specialist physicians. Surgical providers performed a median of one operation per week, and there were large disparities in operative productivity within the surgical workforce.

Global targets recommend a minimum threshold of 20 surgical, anaesthetic and obstetric specialist physicians per 100,000 population by 2030 [3]; with three specialist anaesthesiologists, we identified a critically low density of surgical specialists in Liberia. Furthermore, the specialist workforce is maldistributed, with the lowest presence of specialists in areas where population poverty is high. To avoid increasing inequality in health, strategies to strengthen surgical human resources should not only focus on increasing the number of surgical providers, but also seek to distribute these more equally. Clear policies on workforce distribution can be an important tool to retain health workers in rural areas and counteract disparities in health [26].

Increasing the number of surgical providers is one of several strategies that should be explored if total surgical volume is to be increased effectively, especially in countries where population numbers are growing [27]. Surgical provider productivity is an important measure because increasing individual operative productivity is one way of boosting surgical volumes. Building surgical teams where specialized providers train and supervise more numerous non-specialist physicians who can deal with a larger volume of less complicated cases may increase the workforce productivity. Equally important, provider volume is known to be closely related to surgical outcomes $[28,29]$. The present study highlighted major disparities in surgical provider productivity, and many providers are rarely entering the operating theatre. The explanation for low productivity is probably complex, as barriers to surgical care in low-resource settings include cultural, financial and structural elements [30]. Nonetheless, one striking aspect is the improved productivity among residents working in areas where the population poverty is higher. These areas all have fewer surgical providers, which might make it easier for the residents to access the operation theatre. The low productivity illustrates how in-depth descriptions can be a steppingstone for further investigations into underlying causes and thereby contribute to building solid fundaments for new policies.

The Lancet Commission on Global Surgery suggested to benchmark and monitor the surgical workforce through specialist provider density [3]. In Liberia, 58 percent of all operations are performed by non-specialist physicians, and 
Table 2 Association between surgical provider characteristics and operative productivity

\begin{tabular}{|c|c|c|c|c|c|}
\hline & \multirow{2}{*}{$\begin{array}{l}\text { Surgical providers } \\
(n)^{\mathrm{a}}\end{array}$} & \multicolumn{2}{|l|}{ Univariable model } & \multicolumn{2}{|l|}{ Multivariable model } \\
\hline & & $\begin{array}{l}\text { Operative productivity ratio } \\
(95 \% \mathrm{CI})\end{array}$ & $P$ & $\begin{array}{l}\text { Operative productivity ratio } \\
(95 \% \mathrm{CI})\end{array}$ & $P$ \\
\hline \multicolumn{6}{|l|}{$\begin{array}{l}\text { Range of essential } \\
\text { procedures }\end{array}$} \\
\hline $0-1$ & 84 & 1.00 (reference) & & 1.00 (reference) & \\
\hline 2 & 59 & $2.67(1.94-3.67)$ & $<0.001$ & $2.81(2.04-3.90)$ & $<0.001$ \\
\hline 3 & 38 & $4.24(2.97-6.07)$ & $<0.001$ & $4.19(2.92-6.03)$ & $<0.001$ \\
\hline $4-6$ & 53 & $5.49(3.98-7.58)$ & $<0.001$ & $4.49(3.25-6.20)$ & $<0.001$ \\
\hline $7-14$ & 49 & $14.20(10.26-19.65)$ & $<0.001$ & $8.66(6.27-11.97)$ & $<0.001$ \\
\hline \multicolumn{6}{|l|}{ Caesarean section } \\
\hline Performing & 206 & 1.00 (reference) & & 1.00 (reference) & \\
\hline Not performing & 77 & $0.37(0.27-0.52)$ & $<0.001$ & $0.45(0.32-0.62)$ & $<0.001$ \\
\hline \multicolumn{6}{|l|}{ Laparotomy } \\
\hline Performing & 85 & 1.00 (reference) & & 1.00 (reference) & \\
\hline Not performing & 198 & $0.31(0.23-0.42)$ & $<0.001$ & $0.41(0.31-0.54)$ & $<0.001$ \\
\hline \multicolumn{6}{|l|}{ Open fracture treatment } \\
\hline Performing & 11 & 1.00 (reference) & & 1.00 (reference) & \\
\hline Not performing & 272 & $0.34(0.16-0.72)$ & 0.005 & $0.44(0.22-0.88)$ & 0.021 \\
\hline \multicolumn{6}{|l|}{ Provider specialization } \\
\hline Specialist & 66 & 1.00 (reference) & & 1.00 (reference) & \\
\hline Resident & 48 & $0.57(0.35-0.93)$ & 0.024 & $0.96(0.60-1.52)$ & 0.854 \\
\hline Non-specialist physician & 152 & $0.86(0.60-1.25)$ & 0.435 & $0.82(0.57-1.19)$ & 0.302 \\
\hline Non-physician & 17 & $0.45(0.22-0.90)$ & 0.024 & $0.48(0.25-0.93)$ & 0.030 \\
\hline \multicolumn{6}{|l|}{ Provider nationality } \\
\hline Liberian & 218 & 1.00 (reference) & & 1.00 (reference) & \\
\hline Foreign & 65 & $1.70(1.19-2.42)$ & 0.004 & $1.62(1.17-2.25)$ & 0.004 \\
\hline \multicolumn{6}{|l|}{ Working position } \\
\hline Full time & 141 & 1.00 (reference) & & 1.00 (reference) & \\
\hline Part time & 142 & $0.45(0.34-0.60)$ & $<0.001$ & $1.09(0.83-1.44)$ & 0.545 \\
\hline \multicolumn{6}{|l|}{ Working area } \\
\hline Area with lower poverty ${ }^{\mathrm{b}}$ & 126 & 1.00 (reference) & & 1.00 (reference) & \\
\hline $\begin{array}{l}\text { Area with intermediate } \\
\text { poverty }^{c}\end{array}$ & 113 & $0.94(0.67-1.31)$ & 0.697 & $0.77(0.50-1.19)$ & 0.244 \\
\hline Area with higher poverty ${ }^{\mathrm{d}}$ & 44 & $0.92(0.59-1.44)$ & 0.716 & $0.83(0.49-1.40)$ & 0.487 \\
\hline
\end{tabular}

${ }^{\mathrm{a}}$ Three missing values on provider productivity; ${ }^{\mathrm{b}}$ Area where $<30 \%$ of people live in absolute poverty; ${ }^{\mathrm{c}}$ Area where $30-70 \%$ of people live in absolute poverty; ${ }^{\mathrm{d}}$ Area where $>70 \%$ of people live in absolute poverty

these providers are the backbone of surgical services outside the capital area. Non-specialist physicians are known to be major contributors to surgical care in sub-Saharan Africa [31, 32], but their presence is currently not captured by global benchmarking metrics. This study highlights that non-specialist physicians can be major contributors to national surgical volumes, and they may also be part of the solution in making surgical services more available. Hence, their presence should be recognized, measured and monitored.
Total surgical volume is an important metric for global surgery benchmarking [3]. Differentiating priority levels for operations by categorizing them as essential or not has been suggested as the next step within surgical volume benchmarking [23]. Almost 90 percent of all operations in this study was categorized as essential, indicating a high population impact. However, the median surgical provider only performed two different types of essential procedures, most commonly caesarean section and hernia repair. A limited availability of essential procedures has also been 
Table 3 Association between facility characteristics and surgical provider operative productivity

\begin{tabular}{|c|c|c|c|c|c|}
\hline & \multirow{2}{*}{$\begin{array}{l}\text { Surgical providers } \\
(n)^{\mathrm{a}}\end{array}$} & \multicolumn{2}{|l|}{ Univariable model } & \multicolumn{2}{|l|}{ Multivariable model } \\
\hline & & $\begin{array}{l}\text { Operative productivity ratio }(95 \% \\
\mathrm{CI})\end{array}$ & $P$ & $\begin{array}{l}\text { Operative productivity ratio }(95 \% \\
\text { CI) }\end{array}$ & $P$ \\
\hline \multicolumn{6}{|l|}{ Facility owner } \\
\hline Governmental & 183 & 1.00 (reference) & & 1.00 (reference) & \\
\hline Private non-profit & 68 & $1.41(0.99-2.03)$ & 0.060 & $2.82(1.71-4.65)$ & $<0.001$ \\
\hline Private for-profit & 32 & $0.99(0.60-1.61)$ & 0.956 & $1.44(0.85-2.45)$ & 0.178 \\
\hline \multicolumn{6}{|l|}{$\begin{array}{l}\text { Facility infrastructure } \\
\text { score }\end{array}$} \\
\hline $97-148$ & 79 & 1.00 (reference) & & 1.00 (reference) & \\
\hline $149-157$ & 90 & $0.99(0.68-1.46)$ & 0.952 & $1.23(0.78-1.92)$ & 0.371 \\
\hline $158-164$ & 42 & $1.57(0.97-2.53)$ & 0.068 & $1.29(0.74-2.28)$ & 0.372 \\
\hline 165 & 72 & $0.83(0.55-1.26)$ & 0.378 & $1.17(0.73-1.88)$ & 0.512 \\
\hline \multicolumn{6}{|c|}{$\begin{array}{l}\text { Surgical providers per } \\
\text { facility }\end{array}$} \\
\hline $1-4$ & 68 & 1.00 (reference) & & 1.00 (reference) & \\
\hline $5-11$ & 78 & $0.74(0.48-1.12)$ & 0.153 & $0.68(0.42-1.09)$ & 0.107 \\
\hline $12-17$ & 72 & $0.83(0.54-1.27)$ & 0.386 & $0.79(0.43-1.43)$ & 0.429 \\
\hline $18-37$ & 65 & $0.65(0.42-1.01)$ & 0.056 & $0.74(0.32-1.75)$ & 0.500 \\
\hline \multicolumn{6}{|l|}{ Surgeon specialist ${ }^{\mathrm{b}}$} \\
\hline Present & 133 & 1.00 (reference) & & 1.00 (reference) & \\
\hline Not present & 150 & $1.27(0.94-1.73)$ & 0.123 & $1.15(0.76-1.74)$ & 0.504 \\
\hline \multicolumn{6}{|l|}{ Ob/gyn specialist ${ }^{\mathrm{b}}$} \\
\hline Present & 117 & 1.00 (reference) & & 1.00 (reference) & \\
\hline Not present & 166 & $1.40(1.03-1.91)$ & 0.032 & $1.22(0.87-1.71)$ & 0.252 \\
\hline \multicolumn{6}{|c|}{ Anaesthesiologist specialist $\mathrm{t}^{\mathrm{b}}$} \\
\hline Present & 55 & 1.00 (reference) & & 1.00 (reference) & \\
\hline Not present & 228 & $1.41(0.96-2.09)$ & 0.082 & $1.48(0.71-3.11)$ & 0.295 \\
\hline
\end{tabular}

${ }^{\mathrm{a}}$ Three missing values on provider productivity; ${ }^{\mathrm{b}}$ At least one specialist available at the facility where the surgical provider works

described at the facility level in Liberia [14], implying that many essential operations are not being performed. This should be seen in the context of low surgical volumes [14], which is far below the Lancet Commission threshold [3], showing that 91 percent of the recommended surgical volume is unmet. Benchmarking metrics should not only include aggregated surgical volume, but also describe the availability of the separate essential procedures to provide a better understanding of the challenges and opportunities within the surgical system.

As global surgery develops, there is an increasing momentum to construct national surgical, obstetric and anaesthesia plans, and these plans should be based on national assessments of the surgical system, including the specialist workforce [17]. In Liberia, the operative productivity among specialists was low, and the difference in productivity between specialists and non-specialist physicians was small. This raises questions about the comparability of specialists across settings where surgical volumes are very different. It may be the case that specialists mainly supervise and act as support for less experienced first operators. However, if this was the case, one would expect providers working in facilities with specialists present to be more productive, but such a difference was not detected. Due to the immense heterogeneity between nations and the nature of their health systems, local metrics should reflect local circumstances [33]. A focus on specialists alone will in many low- and middleincome countries only describe a minor fraction of the full surgical workforce. Consequently, overarching global metrics should be disaggregated when used at the national level to set aspirational targets for national plans.

This study is to the best of our knowledge the most comprehensive assessment of the surgical workforce in Liberia to date, creating a foundation for recommendations (Textbox). However, some limitations should be 
Table 4 Association between available safe surgery items and surgical provider productivity

\begin{tabular}{|c|c|c|c|c|c|}
\hline & \multirow{2}{*}{$\begin{array}{l}\text { Surgical providers } \\
(n)^{\mathrm{a}}\end{array}$} & \multicolumn{2}{|l|}{ Univariable model } & \multicolumn{2}{|l|}{ Multivariable model } \\
\hline & & $\begin{array}{l}\text { Operative productivity ratio ( } 95 \% \\
\text { CI) }\end{array}$ & $P$ & $\begin{array}{l}\text { Operative productivity ratio }(95 \% \\
\text { CI) }\end{array}$ & $P$ \\
\hline \multicolumn{6}{|c|}{ Safe surgery items } \\
\hline \multicolumn{6}{|c|}{ Oxygen } \\
\hline Available & 186 & 1.00 (reference) & & 1.00 (reference) & \\
\hline Not available & 97 & $0.87(0.63-1.20)$ & 0.401 & $0.62(0.42-0.90)$ & 0.012 \\
\hline \multicolumn{6}{|l|}{ Pulse oximetry } \\
\hline Available & 270 & 1.00 (reference) & & 1.00 (reference) & \\
\hline Not available & 13 & $0.96(0.46-1.98)$ & 0.904 & $1.34(0.65-2.74)$ & 0.431 \\
\hline \multicolumn{6}{|l|}{ Sterilizer } \\
\hline Available & 283 & 1.00 (reference) & & 1.00 (reference) & \\
\hline Not available & 0 & - & - & - & - \\
\hline \multicolumn{6}{|c|}{ Skin preparation solution } \\
\hline Available & 280 & 1.00 (reference) & & 1.00 (reference) & \\
\hline Not available & 3 & $0.29(0.058-1.46)$ & 0.133 & $0.18(0.041-0.78)$ & 0.022 \\
\hline \multicolumn{6}{|l|}{ Sterile gloves } \\
\hline Available & 278 & 1.00 (reference) & & 1.00 (reference) & \\
\hline Not available & 5 & $0.91(0.28-2.92)$ & 0.874 & $0.90(0.31-2.65)$ & 0.850 \\
\hline \multicolumn{6}{|l|}{ Suction } \\
\hline Available & 280 & 1.00 (reference) & & 1.00 (reference) & \\
\hline Not available & 3 & $0.74(0.16-3.33)$ & 0.691 & $0.61(0.15-2.44)$ & 0.487 \\
\hline \multicolumn{6}{|l|}{ Adult mask bag } \\
\hline Available & 283 & 1.00 (reference) & & 1.00 (reference) & \\
\hline Not available & 0 & - & - & - & - \\
\hline \multicolumn{6}{|c|}{ Intravenous fluids } \\
\hline Available & 239 & 1.00 (reference) & & 1.00 (reference) & \\
\hline Not available & 44 & $0.85(0.56-1.29)$ & 0.442 & $0.72(0.47-1.11)$ & 0.134 \\
\hline \multicolumn{6}{|c|}{ All safe surgery items } \\
\hline Available & 163 & 1.00 (reference) & & 1.00 (reference) & \\
\hline Not available & 120 & $0.91(0.67-1.24)$ & 0.543 & $0.73(0.49-1.07)$ & 0.110 \\
\hline \multicolumn{6}{|c|}{$\begin{array}{l}\text { Blood } \\
\quad \text { available }<30 \mathrm{~min}\end{array}$} \\
\hline Available & 239 & 1.00 (reference) & & 1.00 (reference) & \\
\hline Not available & 44 & $0.82(0.54-1.25)$ & 0.360 & $0.60(0.39-0.93)$ & 0.020 \\
\hline \multicolumn{6}{|c|}{ Safe surgery checklist } \\
\hline Utilized & 117 & 1.00 (reference) & & 1.00 (reference) & \\
\hline Not utilized & 166 & $0.99(0.72-1.35)$ & 0.935 & $0.99(0.67-1.48)$ & 0.975 \\
\hline
\end{tabular}

${ }^{a}$ Three missing values on provider productivity

considered when interpreting the results. Firstly, the operative characteristics rely on a 4-month sample, and although the sample scale up to 12 months correlated well with the actual count from all 12 months [14], there is a chance that some seasonal variation was missed. Furthermore, surgical providers were identified through the 4-month sample, and it is possible that surgeons practicing in-between these 4 months were missed. Additionally, only the first operator was counted, and the efforts from second operators were not captured. It may be the case that experienced providers mainly teach and supervise as second operator, and such efforts are not reflected in the individual operative productivity measure. Another limitation is that this study did not provide complementary information on anaesthesia capabilities that may influence operative productivity. Lastly, the functionality of safe 
surgery items was not systematically assessed through inspection, and some of these items may have been considered inadequate for its use if more detailed information had been obtained.

Textbox: Recommendations to strengthen reporting metrics and improve the surgical system globally and locally in Liberia

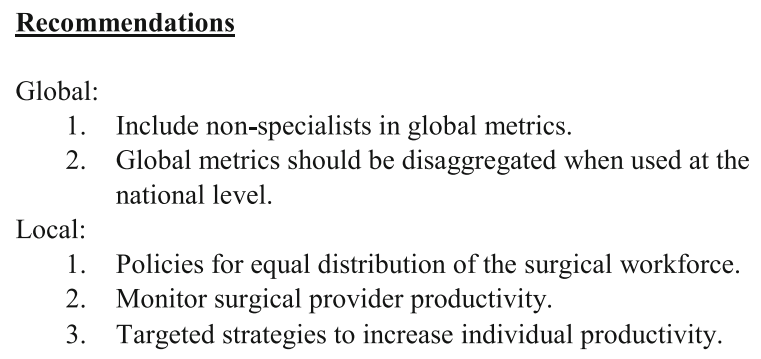

This study has highlighted a critical shortage of surgical providers in Liberia, and specialists are particularly deficient. Furthermore, most of the surgical workforce is rarely entering the operating theatre, which raises concerns about the quality of care. However, this challenge also offers an opportunity to boost surgical volumes if productivity can be lifted. Comprehensive training that allows providers to offer a broader range of essential procedures may also allow them to be more productive. This study also demonstrates that disaggregated data analysed at the lowest level of resolution can highlight challenges and opportunities and inform national planning. Such analysis can separate facility-level trends from provider-level trends and can lead to good targets at each level. The evolution of surgical system assessments and reporting metrics will be key if the global surgery movement is to keep its course towards universal health coverage.

Acknowledgements We want to thank all collaborating partners in Liberia for making the data collection for this study possible. We also want to thank Torunn and Oles Foundation, a Norwegian non-governmental organization, for funding the data collection for this study. The funding source had no role in any aspect of the study.

Funding Open access funding provided by NTNU Norwegian University of Science and Technology (incl St. Olavs Hospital Trondheim University Hospital).

Open Access This article is licensed under a Creative Commons Attribution 4.0 International License, which permits use, sharing, adaptation, distribution and reproduction in any medium or format, as long as you give appropriate credit to the original author(s) and the source, provide a link to the Creative Commons licence, and indicate if changes were made. The images or other third party material in this article are included in the article's Creative Commons licence, unless indicated otherwise in a credit line to the material. If material is not included in the article's Creative Commons licence and your intended use is not permitted by statutory regulation or exceeds the permitted use, you will need to obtain permission directly from the copyright holder. To view a copy of this licence, visit http://creativecommons. org/licenses/by/4.0/.

\section{References}

1. Vos T, Lim SS, Abbafati C et al (2020) Global burden of 369 diseases and injuries in 204 countries and territories, 1990-2019: a systematic analysis for the Global Burden of Disease Study 2019. Lancet 396:1204-1222

2. Norheim OF, Jha P, Admasu K et al (2015) Avoiding $40 \%$ of the premature deaths in each country, 2010-30: review of national mortality trends to help quantify the UN sustainable development goal for health. Lancet 385:239-252

3. Meara JG, Leather AJ, Hagander L et al (2015) Global Surgery 2030: evidence and solutions for achieving health, welfare, and economic development. Lancet 386:569-624

4. Mock CN, Donkor P, Gawande A, Essential Surgery: key Messages of this volume, et al (2015) In: Disease Control Priorities, Third Edition (Volume 1): Essential Surgery, Debas HT, Donkor P, Gawande A, Jamison DT, Kruk ME. Mock CN. World Bank Publications, Washington, pp 1-18

5. Holmer H, Lantz A, Kunjumen T et al (2015) Global distribution of surgeons, anaesthesiologists, and obstetricians. Lancet Glob Health 3(Suppl 2):9-11

6. World Health Organization (2017) Surgical care systems strengthening: developing national surgical, obstetric and anaesthesia plans. https://apps.who.int/iris/handle/10665/255566 . Accessed 23 June 2021.

7. Cossa M, Rose J, Berndtson AE et al (2021) Assessment of Surgical Care Provided in National Health Services Hospitals in Mozambique: the importance of subnational metrics in global surgery. World J Surg 45:1306-1315

8. Bolkan HA, Hagander L, von Schreeb J et al (2016) The surgical workforce and surgical provider productivity in sierra leone: a countrywide inventory. World J Surg 40:1344-1351

9. Gajewski J, Borgstein E, Bijlmakers L et al (2019) Evaluation of a surgical training programme for clinical officers in Malawi. Br J Surg 106:e156-e165

10. Holmer H, Bekele A, Hagander L et al (2019) Evaluating the collection, comparability and findings of six global surgery indicators. Br J Surg 106:e138-e150

11. United Nations (2020) Human Development Reports. http://hdr. undp.org/en/content/latest-human-development-index-ranking . Accessed 23 June 2021.

12. Ministry of Health, Government of Liberia (2015) Investment Plan for Building a Resilient Health System, Liberia: 2015 to 2021. https://www.resilientinstitutionsafrica.org/resources/invest ment-plan-building-resilient-health-system-2015-2021 . Accessed 24 June 2021.

13. Knowlton LM, Chackungal S, Dahn B et al (2013) Liberian surgical and anesthesia infrastructure: a survey of county hospitals. World J Surg 37:721-729

14. Adde HA, van Duinen AJ, Oghogho MD et al (2020) Impact of surgical infrastructure and personnel on volume and availability of essential surgical procedures in Liberia. BJS Open 4:1246-1255

15. World Directory of Medical Schools, A.M. Dogliotti College of Medicine, University of Liberia. https://search.wdoms.org/home/ SchoolDetail/F0001595. Accessed 24 June 2021.

16. American International Health Alliance (2017) Liberia Hospitalbased Residency Training Program Accreditation Assessment Visit. https://www.aiha.com/wp-content/uploads/2018/09/ Liberia-Assessment-Report-FINAL.pdf . Accessed 24 June 2021. 
17. Sonderman KA, Citron I, Mukhopadhyay S et al (2019) Framework for developing a national surgical, obstetric and anaesthesia plan. BJS Open 3:722-732

18. Bowman KG, Jovic G, Rangel S et al (2013) Pediatric emergency and essential surgical care in Zambian hospitals: a nationwide study. J Pediatr Surg 48:1363-1370

19. Esquivel MM, Uribe-Leitz T, Makasa E et al (2016) Mapping disparities in access to safe, timely, and essential surgical care in Zambia. JAMA Surg 151:1064-1069

20. Weiser TG, Regenbogen SE, Thompson KD et al (2008) An estimation of the global volume of surgery: a modelling strategy based on available data. Lancet 372:139-144

21. Liberia Institute of Statistics \& Geo-Information Service (2017) Household Income and Expenditure Survey 2016 Statistical Abstract. https://microdata.worldbank.org/index.php/catalog/ 2986/related-materials. Accessed 23 June 2021.

22. Liberia Insitute of Statistics and Geo-Information Service (2009) 2008 Population and Housing Census. http://www.lisgis.net/pg img/NPHC\%202008\%20Final\%20Report.pdf . Accessed 24 June 2021.

23. Gyedu A, Stewart B, Gaskill C et al (2018) Improving benchmarks for global surgery: nationwide enumeration of operations performed in Ghana. Ann Surg 268:282-288

24. RStudio Team (2020) RStudio: Integrated Development Environment for R. http://www.rstudio.com/ . Accessed 24 June 2021.

25. Bates D, Mächler M, Bolker B et al (2015) Fitting linear mixedeffects models using lme4. J Stat Softw 67:48

26. World Health Organization (2010) Increasing access to health workers in remote and rural areas through improved retention. https://apps.who.int/iris/handle/10665/44369. Accessed 30 March 2021.

27. Lindheim-Minde B, Gjøra A, Bakker JM et al (2021) Changes in surgical volume, workforce, and productivity in Sierra Leone between 2012 and 2017. Surgery 170:126-133

28. Morche J, Mathes T, Pieper D (2016) Relationship between surgeon volume and outcomes: a systematic review of systematic reviews. Syst Rev 5:204

29. Birkmeyer JD, Stukel TA, Siewers AE et al (2003) Surgeon volume and operative mortality in the United States. N Engl J Med 349:2117-2127

30. Grimes CE, Bowman KG, Dodgion CM et al (2011) Systematic review of barriers to surgical care in low-income and middleincome countries. World J Surg 35:941-950

31. Bishop D, Dyer RA, Maswime S et al (2019) Maternal and neonatal outcomes after caesarean delivery in the African Surgical Outcomes Study: a 7-day prospective observational cohort study. Lancet Glob Health 7:e513-e522

32. Hoyler M, Hagander L, Gillies R et al (2015) Surgical care by non-surgeons in low-income and middle-income countries: a systematic review. Lancet 385:S42

33. World Health Organization (2002) Health in sustainable development planning: the role of indicators/Yasmin von Schirnding. https://apps.who.int/iris/handle/10665/67391. Accessed 24 June 2021.

Publisher's Note Springer Nature remains neutral with regard to jurisdictional claims in published maps and institutional affiliations. 